\title{
Crescimento e produção de repolho em função de doses de nitrogênio
}

\author{
Marialva A Moreira; Sanzio M Vidigal; Maria Aparecida N Sediyama; Marlei Rosa dos Santos \\ EPAMIG, Vila Gianetti, 46, 36571-000 Viçosa-MG; mam@vicosa.ufv.br; sanziomv@epamig.ufv.br
}

\section{RESUMO}

O manejo adequado do programa da adubação na cultura do repolho pode ser conseguido pela sincronização da demanda da planta com o suprimento de $\mathrm{N}$ durante o ciclo da cultura. $\mathrm{O}$ objetivo deste trabalho foi determinar a influência de doses de nitrogênio no acúmulo de massa da matéria seca e na produção, em diferentes fases do desenvolvimento da planta de repolho, híbrido Shutoku. O experimento foi conduzido na EPAMIG, Oratórios-MG, de 02/07 a 13/10/08. Os tratamentos, cinco doses de N $(0 ; 75 ; 150 ; 300$ e $\left.450 \mathrm{~kg} \mathrm{ha}^{-1}\right)$, foram arranjados no delineamento experimental de blocos ao acaso, com quatro repetições. Aos 50, 64 e 78 dias após a semeadura foram avaliadas as características de crescimento das plantas: comprimento do caule, número de folhas, massa da matéria fresca e seca de folhas, caules e raízes e $\mathrm{N}$ na massa seca. A colheita final das cabeças de repolho ocorreu aos 103 dias após a semeadura. A maior produção de massa da matéria fresca da cabeça de repolho foi de $1,13 \mathrm{~kg}$ obtido com a dose de $277,8 \mathrm{~kg} \mathrm{~N} \mathrm{ha}^{-1}$. Com a dose ótima de $\mathrm{N}$ para a produção, os valores ótimos estimados para os teores foliares de $\mathrm{N}-\mathrm{NO}_{3}$ e de nitrogênio total variaram com a época de amostragem. $\mathrm{O}$ período inicial de maior acúmulo de massa da matéria seca variou com as doses de nitrogênio.

Palavras-chave: Brassica oleracea var. capitata L., adubação, nutrição mineral.

\begin{abstract}
Growth and yield of cabbage depending on nitrogen rates

The appropriate program of fertilization for the cabbage crop can be obtained through the synchronization of the plant demand of the plant with the supply of $\mathrm{N}$ during the cycle. We determined the influence of rates of nitrogen in the accumulation of dry weight and in the yield, in different phases of the development of cabbage hybrid Shutoku. The experiment was carried out in EPAMIG, Oratorios, Minas Gerais State, Brazil, from July $2^{\text {th }}$ to October $10^{\text {th }}, 2008$. Five rates of $\mathrm{N}$ were evaluated $\left(0,75,150,300\right.$ and $\left.450 \mathrm{~kg} \mathrm{ha}^{-1}\right)$. Each treatment was set in randomized block design with four replications. At 50, 64 and 78 days after seeding, the characteristics of growth of the plants, length of the stem, number of leaves, fresh and dry weight of leaves, stems and roots and $\mathrm{N}$ content in the dry weight were measured. The harvest occurred at 103 days after seeding. The highest production of cabbage head fresh weight was of $1.13 \mathrm{~kg}$ obtained with the rate of $277.8 \mathrm{~kg} \mathrm{~N} \mathrm{ha}^{-1}$. With the optimal rate of $\mathrm{N}$ for the yield, the optimal estimated values for the content of $\mathrm{N}-\mathrm{NO}_{3}$ in leaves and of total nitrogen varied with the sampling time. The initial period of the highest accumulation of dry weight varied with the rates of nitrogen.
\end{abstract}

Keywords: Brassica oleracea var. capitata L., fertilization, mineral nutrition.

(Recebido para publicação em 25 de agosto de 2009; aceito em 20 de dezembro de 2010) (Received on August 25, 2009; accepted on December 20, 2010)

$\mathrm{O}$ repolho (Brassica oleracea var. capitata) é hortaliça herbácea, com folhas arredondadas e cerosas, formando uma cabeça compacta. Ao longo do tempo, foram obtidas cultivares adaptadas a temperaturas elevadas, ampliando conseqüentemente os períodos de plantio e de colheita. Assim, pela escolha criteriosa da cultivar, a época de plantio estende-se ao longo do ano, em diversas regiões produtoras (Filgueira, 2007).

A fertilização com nitrogênio aumenta a produção (Huang et al., 2004; Aquino et al., 2005a; Din et al., 2007) e otimiza a qualidade de repolho (Aquino et al., 2005b; Haque et al., 2006). Dose reduzida de nitrogênio pode resultar em baixa produtividade e cabeças menores, devido à reduzida área foliar (Cardoso \& Hiraki, 2001; Torres et al., 2003). Por outro lado, dose muito alta de nitrogênio favorece o crescimento excessivo das folhas, reduz os teores de açúcares e de vitamina $\mathrm{C}$ e a massa da matéria seca da cabeça (Din et al., 2007; Kano et al., 2007). Portanto, é necessário manejar adequadamente o programa de adubação na cultura.

Melhoria na eficiência de aplicação do nitrogênio pode ser conseguida pela sincronização da demanda da planta com o suprimento de nitrogênio durante o ciclo da cultura. A dose de nitrogênio deve ser sincronizada com o requerimento de nitrogênio em tempo real através de aplicações periódicas de nitrogênio. Isso pode ser conseguido aplicando-se uma parte do adubo nitrogenado no plantio e o restante parcelado de acordo com a necessidade da planta, definida pela avaliação do estado de nitrogênio da planta.

Uma das maneiras encontradas para avaliar o desempenho das plantas ao longo de dias, semanas, meses ou mesmo durante todo o seu ciclo, nas mais variadas formas de cultivo, é a análise de seu crescimento por meio de medidas de área foliar, da massa da matéria seca e do número de unidades estruturais, determinando-se qual ou quais são as cultivares mais produtivas em determinado sistema de cultivo utilizado ou ambiente (Benincasa, 1988). O objetivo deste trabalho foi determinar a influência de doses de nitrogênio no acúmulo de massa da matéria seca e na produção, em diferentes fases do desenvolvimento da planta de repolho.

\section{MATERIAL E MÉTODOS}

O experimento foi conduzido na fazenda experimental da EPAMIG, Oratórios-MG, de 02/07 a 13/10/08, utilizando-se o híbrido Shutoku. Em 
função da recomendação de $150 \mathrm{~kg} \mathrm{ha}^{-1}$ de $\mathrm{N}$ para a cultura do repolho em Minas Gerais (Ribeiro et al., 1999), foram avaliadas cinco doses de $\mathrm{N}(0 ; 75 ; 150 ; 300$ e $450 \mathrm{~kg} \mathrm{ha}^{-1}$ ), sendo cada dose aplicada em cobertura, em três parcelas iguais, aos 43, 57 e 71 dias após a semeadura, tendo a uréia como fonte de nitrogênio. Os tratamentos foram arranjados no delineamento experimental de blocos ao acaso, com quatro repetições. A semeadura ocorreu em 02/07, em bandejas de poliestireno expandido com 128 células preenchidas com substrato comercial Plantmax $^{\circledR}$. O transplantio das mudas ocorreu em 04/08/08, tendo as mesmas de 3-4 folhas completas, utilizando-se o espaçamento de $0,4 \times 0,5 \mathrm{~m}$. A parcela foi constituída de oito linhas com 15 plantas cada e a parcela útil constou de 44 plantas das quatro linhas centrais.

O solo, Argissolo Vermelho-Amarelo, da área de cultivo apresentou, na camada de 0-20 $\mathrm{cm}$ de profundidade as seguintes características: $\mathrm{pH}$ (água) $=$ 4,5; $\mathrm{Ca}=1,0 ; \mathrm{Mg}=0,3 ; \mathrm{Al}=0,5 ; \mathrm{H}+\mathrm{Al}=$ 3,96, expressos em cmol $\mathrm{dm}^{-3}, \mathrm{P}=21,8$ $\mathrm{mg} \mathrm{dm}^{-3}$ (Mehlich 1); $\mathrm{K}=43,0 \mathrm{mg} \mathrm{dm}^{-3}$ e matéria orgânica $=11,0 \mathrm{~g} \mathrm{~kg}^{-1}$. Na correção da acidez do solo, a calagem foi realizada com a aplicação de 4,0 t ha $^{-1}$ de calcário dolomítico.

O preparo do solo constou de aração, gradagem e abertura dos sulcos com $15 \mathrm{~cm}$ de profundidade. A adubação de plantio foi definida de acordo com a recomendação para a cultura do repolho (Vidigal et al., 2007), consistiu de $1.500 \mathrm{~kg} \mathrm{ha}^{-1}$ de superfosfato simples, $80 \mathrm{~kg} \mathrm{ha}^{-1}$ de cloreto de potássio, 20 $\mathrm{kg} \mathrm{ha}^{-1}$ de bórax e $20 \mathrm{~kg} \mathrm{ha}^{-1}$ de sulfato de zinco. Utilizou-se também $100 \mathrm{~kg}$ ha $^{-1}$ de cloreto de potássio, aplicado em duas parcelas, juntamente com a primeira e segunda aplicação do adubo nitrogenado, em cobertura. Os tratos culturais, controle de pragas e irrigação por microaspersão foram realizados de acordo com as necessidades, conforme recomendações para a cultura (Vidigal et al., 2007).

As avaliações foram feitas aos sete dias após a aplicação de nitrogênio em cada tratamento, sendo realizadas aos 50, 64 e 78 dias após a semeadura. Em cada data de coleta foram colhidas quatro plantas de cada parcela. Essas foram acondicionadas em sacos plásticos, levadas para o laboratório, separadas em folhas, caules e raízes, pesadas para obtenção da massa da matéria fresca de cada órgão. Em seguida, mediu-se o comprimento do caule e contou-se o número de folhas.

Posteriormente, as massas da matéria fresca de folhas, caules e raízes foram acondicionadas em sacos de papel e colocadas em estufa de circulação forçada de ar a $70^{\circ} \mathrm{C}$ até atingir massa constante quando foi determinada a massa da matéria seca. Após a secagem, o material foi moído em moinho tipo Wiley, equipado com peneira de 20 mesh, submetido à digestão sulfúrica para a determinação dos teores de $\mathrm{N}$ por titulometria após destilação em microdestilador de Kjeldahl. Em outra subamostra, o N-NO foi extraído com água desmineralizada em banho-maria, a $45^{\circ} \mathrm{C}$ por $1 \mathrm{~h}$, determinando-se a concentração de $\mathrm{N}_{-} \mathrm{NO}_{3}$ por colorimetria, em espectrofotômetro a $410 \mathrm{~nm}$ (Cataldo et al., 1975).

A colheita ocorreu aos 103 dias após a semeadura, quando a cabeça alcançou a compacidade (firmeza) necessária para o comércio, ou seja ponto ideal de colheita. Em cada parcela foram colhidas seis plantas da área útil, uniformes e representativas do tratamento. Dessas, três cabeças foram imersas em balde com água para medição do volume da cabeça pelo método de deslocamento de água e três foram pesadas para obtenção da massa da matéria fresca. Posteriormente, essas foram seccionadas longitudinalmente, para medições dos diâmetros transversal e longitudinal, com auxílio do paquímetro. Os dados foram submetidos à análise de regressão para o ajuste dos modelos estatísticos de análise de crescimento, pelo método de superfície de resposta e regressão polinomial para análise de produção, utilizando-se o programa SAEG (Funarbe, 1993).

\section{RESULTADOS E DISCUSSÃO}

Houve efeito quadrático $(\mathrm{p}<0,01)$ das doses de nitrogênio sobre a produção de repolho. A produção de massa da matéria fresca da cabeça (MFC) de repolho respondeu acentuadamente ao aumento das doses de nitrogênio (Figura 1).

$\mathrm{O}$ valor máximo estimado da $\mathrm{MFC}$ de $1,13 \mathrm{~kg}$ foi obtido com a dose de $277,8 \mathrm{~kg} \mathrm{~N} \mathrm{ha}^{-1}$. Aumento da massa da matéria fresca da cabeça do repolho com o aumento de doses de nitrogênio foi verificado por Aquino et al. (2005a). Diversos autores têm verificado que a fertilização com nitrogênio aumenta, de maneira considerável, o rendimento de cabeça em condições de campo (Huett

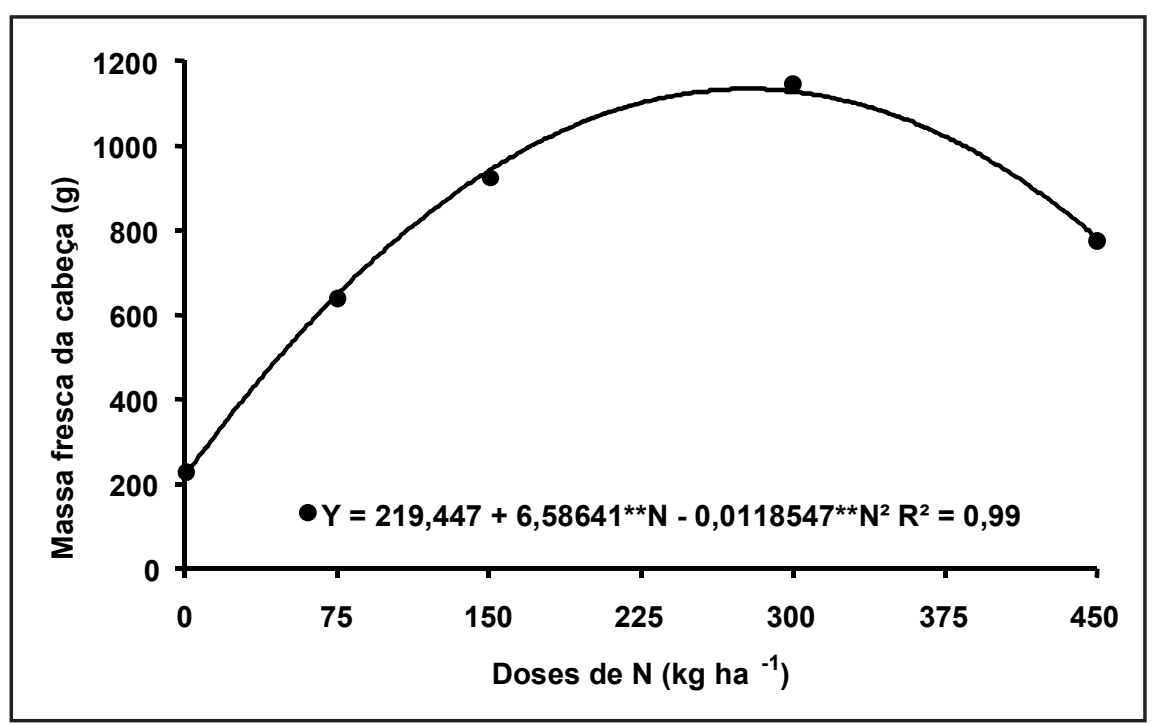

Figura 1. Relação entre os valores de massa da matéria fresca de cabeça de repolho e doses de nitrogênio (relationship among the values of fresh weight (MFC) of cabbage heads and rates of nitrogen). Oratórios-MG, EPAMIG, 2008. ** - significativo a $1 \%$ de probabilidade pelo teste "t." 


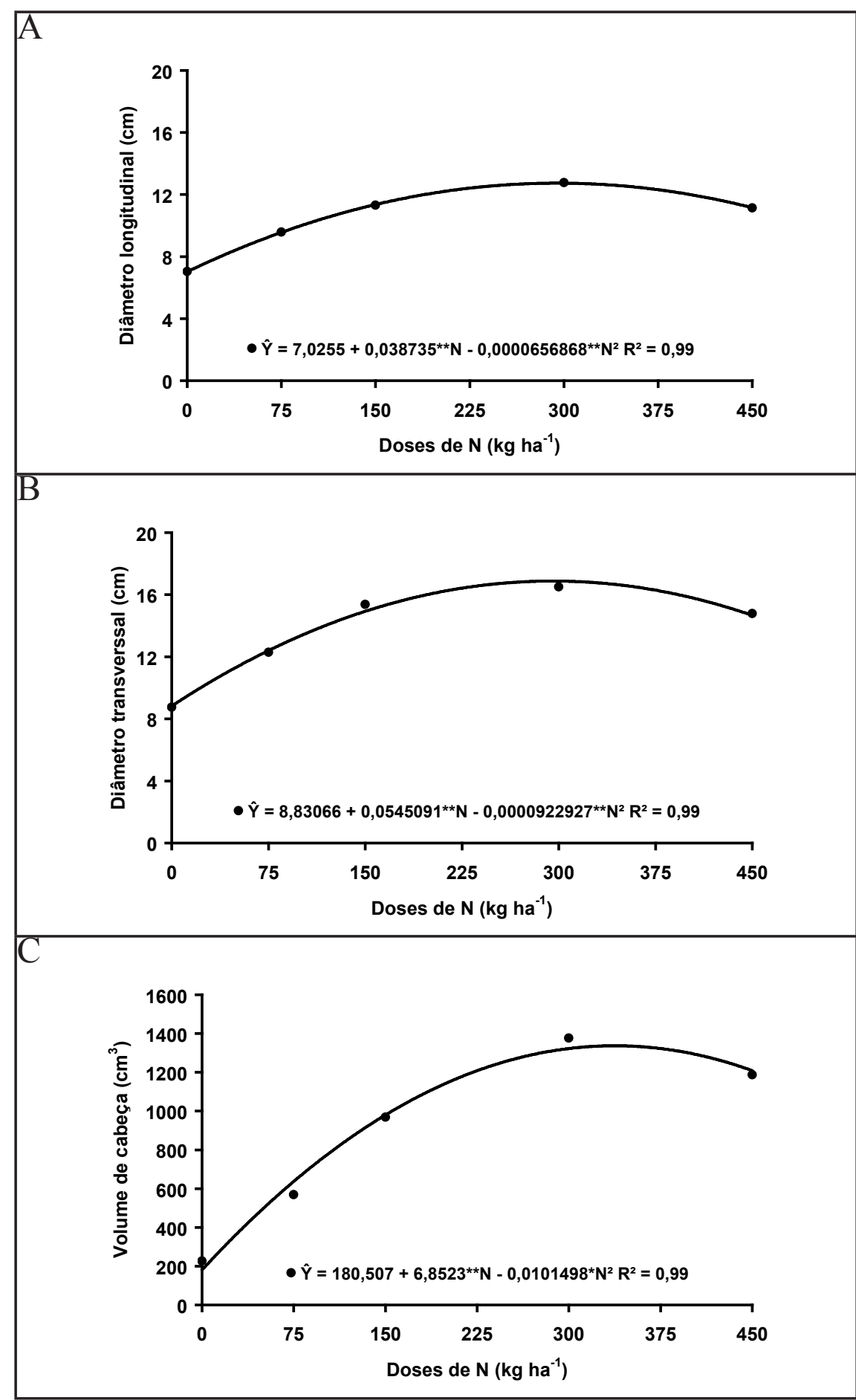

Figura 2. Relação entre os valores dos diâmetros longitudinal (A), transversal (B) e volume de cabeça (C) e doses de nitrogênio (relationship among the values of longitudinal diameter (A), traverse diameter (B) and volume of head (C) and rates of nitrogen). Oratórios-MG, EPAMIG, 2008. ** e *- significativo a 1 e $5 \%$ de probabilidade pelo teste " $\mathrm{t}$ ", respectivamente.

\& Dettmann, 1989; Haque et al., 2006; Din et al., 2007). A intensidade da resposta ao nitrogênio aplicado pode ser variável com diversos fatores, dentre eles a época do ano (Westerveld et al., 2004) e a cultivar (Aquino et al., 2005a).
Esses autores, utilizando híbrido Kenzan obtiveram a máxima eficiência econômica com a dose de $253 \mathrm{~kg} \mathrm{ha}^{-1} \mathrm{de} \mathrm{N}$, nos meses de setembro a dezembro.

Os diâmetros transversal (DT), longitudinal (DL) e o volume (VC) de cabeça aumentaram de forma quadrática $(p<0,05)$ com o incremento das doses de $\mathrm{N}$ (Figura 2).

Com a dose ótima de nitrogênio para a produção, 277, $8 \mathrm{~kg} \mathrm{~N} \mathrm{ha}^{-1}$, os valores ótimos estimados do DT; DL e VC foram de 16,$9 ; 12,7 \mathrm{~cm}$ e $1.300,8 \mathrm{~cm}^{3}$, respectivamente (Figura 2). Estes valores estão próximos aos estimados por Aquino et al. (2005b) que foram 18,8 e $13,7 \mathrm{~cm}$ para o DT e DL, com as doses de 288,6 e $215,4 \mathrm{~kg} \mathrm{~N} \mathrm{ha}^{-1}$, respectivamente. Aumento do volume de cabeça com o aumento de doses de $\mathrm{N}$ foi verificado por Aquino et al. (2005b).

O comprimento do caule (CC), número de folhas (NF) e as massas da matéria seca (MS) de folhas (F) e caules (C) aumentaram com o ciclo da cultura e com o incremento das doses de nitrogênio, exceto a massa da matéria seca de raízes que não foi influenciada pelo ciclo da cultura e doses de nitrogênio, sendo o valor médio de 32,19 g. A falta de resposta da massa seca de raízes ao nitrogênio pode ter ocorrido devido à dificuldade na amostragem, apesar de que em algumas plantas podemos observar menor crescimento de raízes na ausência de nitrogênio. Os modelos que melhor descreveram o efeito de doses de N sobre cada característica estão na Tabela 1.

As massas da matéria seca de folhas e caules aumentaram de forma quadrática com o ciclo da cultura e de forma linear ao aumento das doses de N. O número de folhas aumentou de forma linear com o ciclo da cultura em todas as doses de $\mathrm{N}$. O crescimento inicial foi lento caracterizando uma época de pouco acúmulo de massa seca. Para atingir o máximo de produção, o que foi verificado na dose de $277,8 \mathrm{~kg} \mathrm{~N} \mathrm{ha}^{-1}$, seria necessária maior disponibilidade de nutrientes. Os aumentos do $\mathrm{CC}$ e NF com o incremento na dose de nitrogênio, devem-se ao efeito promovedor do nitrogênio no crescimento (Cardoso \& Hiraki, 2001; Ferreira et al., 2002). Ekbladh et al. (2007) encontraram relação de proporcionalidade entre área foliar e nitrogênio, mostrando relação direta entre expansão da área foliar e absorção de N.

Esses resultados comprovam a importância do nitrogênio no crescimento das plantas de repolho, onde o incremento nas doses de nitrogênio, ao 
Tabela 1. Equações de regressão ajustadas do comprimento do caule (CC), número de folhas (NF), massas da matéria seca de folhas (MSF), caules (MSC) e raízes (MSR) de repolho, em função de ciclo da cultura (E) e doses de nitrogênio (N) e os respectivos coeficientes de determinação (regression equations of the length of stem (CC), number of leaves (NF), dry weight of leaves (MSF), stems (MSC) and roots (MSR) of cabbage, in function of the cycle of the culture $(\mathrm{E})$ and rates of nitrogen $(\mathrm{N})$ and the respective determination coefficients). Oratórios-MG, EPAMIG, 2008.

\begin{tabular}{llc}
\hline Características & \multicolumn{1}{c}{ Equações ajustadas } & $\mathbf{R}^{2}$ \\
\hline $\mathrm{CC}$ & $\hat{\mathrm{Y}}=3,89992-0,141522 * * \mathrm{E}-0,00571990^{*} \mathrm{~N}+0,0010483^{* *} \mathrm{EN}$ & 0,91 \\
$\mathrm{NF}$ & $\hat{\mathrm{Y}}=-8,67653+0,337688^{* *} \mathrm{E}-0,013081^{*} \mathrm{~N}+0,000214235^{*} \mathrm{EN}$ & 0,98 \\
MSF & $\hat{\mathrm{Y}}=591,96-22,0314 * * \mathrm{E}-0,49194 * * \mathrm{~N}+0,20757^{* *} \mathrm{E}^{2}+0,009110^{* *} \mathrm{EN}$ & 0,97 \\
MSC & $\hat{\mathrm{Y}}=18,385-0,83297^{\circ} \mathrm{E}-0,04492 * * \mathrm{~N}+0,009715^{*} \mathrm{E}^{2}+0,000818^{* *} \mathrm{EN}$ & 0,96 \\
MSR & $\hat{\mathrm{Y}}=32,19$ & - \\
\hline
\end{tabular}

**, * e ${ }^{o}$ significativos a 1,5 e $10 \%$ de probabilidade pelo teste " $\mathrm{t}$ ", respectivamente $\left(* *, *\right.$ and ${ }^{\circ}$ significant at 1,5 and $10 \%$ of probability for the test "t", respectively).

Tabela 2. Equações de regressão ajustadas dos teores de nitrato na folha $\left(\mathrm{NO}_{3} \mathrm{~F}\right)$, caule $\left(\mathrm{NO}_{3} \mathrm{C}\right)$ e teores de nitrogênio total na folha ( $\left.\mathrm{NtF}\right)$ e caule $(\mathrm{NtC})$ de repolho, em função de ciclo da cultura $(\mathrm{E})$ e doses de nitrogênio $(\mathrm{N})$ e os respectivos coeficientes de determinação (regression equations of the content of nitrate in leaf $\left(\mathrm{NO}_{3} \mathrm{~F}\right)$, stem $\left(\mathrm{NO}_{3} \mathrm{C}\right)$ and content of total nitrogen in leaf $(\mathrm{NtF})$ and stem $(\mathrm{NtC})$ of cabbage, in function of the cycle of the culture $(\mathrm{E})$ and rates of nitrogen $(\mathrm{N})$ and the respective determination coefficients). Oratórios-MG, EPAMIG, 2008.

\begin{tabular}{llc}
\hline Características & \multicolumn{1}{c}{ Equações ajustadas } & $\mathbf{R}^{2}$ \\
\hline $\mathrm{NO}_{3} \mathrm{~F}$ & $\hat{\mathrm{Y}}=6,5297-0,1852 * \mathrm{E}+0,00476 * * \mathrm{~N}+0,001359 * \mathrm{E}^{2}-0,0000054231 * \mathrm{~N}^{2}$ & 0,87 \\
$\mathrm{NO}_{3} \mathrm{C}$ & $\hat{\mathrm{Y}}=4,0575-0,1146 * * \mathrm{E}-0,00143 * \mathrm{~N}+0,000835 * * \mathrm{E}^{2}+0,00003043 * * \mathrm{EN}$ & 0,86 \\
$\mathrm{NtF}$ & $\hat{\mathrm{Y}}=6,90207-0,0382245 * \mathrm{E}+0,00413757 * * \mathrm{~N}$ & 0,57 \\
$\mathrm{NtC}$ & $\hat{\mathrm{Y}}=7,81613-0,0834191 * * \mathrm{E}-0,00243026 * * \mathrm{~N}$ & 0,89 \\
\hline
\end{tabular}

** e *significativos a 1 e $5 \%$ de probabilidade pelo teste " $t$ ", respectivamente $(* *$ and *significant at 1 and $5 \%$ of probability for the test " $t$ ", respectively).

proporcionar maior disponibilidade do nutriente às plantas, estimulou o crescimento do repolho, resultando em maior produção de massa fresca de cabeças. Entretanto, aumento nas doses de nitrogênio, proporcionou cabeças maiores e com maior massa da matéria fresca que é característica indesejável para o mercado, pois o consumidor brasileiro prefere repolho ("cabeças") de menor tamanho (cabeças com 1,0 a $1,5 \mathrm{~kg}$ de massa fresca).

O teor de nitrato na folha aumentou de forma quadrática com o ciclo da cultura e com as doses de $\mathrm{N}$, enquanto que o teor de nitrato no caule aumentou de forma quadrática com o ciclo da cultura e de forma linear ao aumento das doses de N. Em condições de campo, na época de colheita, Aquino et al. (2005a) encontraram aumento linear no teor de $\mathrm{N}-\mathrm{NO}_{3}$ na matéria seca das folhas de repolho, híbrido Kenzan, com o aumento da dose de $\mathrm{N}$ de 0 a $300 \mathrm{~kg} \mathrm{ha}^{-1}$.

$\mathrm{O}$ teor de $\mathrm{N}$ na folha e caule do repolho aumentou de forma linear com o ciclo da cultura e com as doses de N. Aumento linear em resposta aos incrementos das doses de $\mathrm{N}$ também foram encontrados por Huett \& Dettmann (1989) e Ekbladh et al. (2007). De acordo com Trani \& Raij (1996), a faixa adequada para teores de $\mathrm{N}$ foliar é de 30 a $50 \mathrm{~g} \mathrm{~kg}^{-1}$, portanto os teores foliares obtidos neste trabalho estão acima dessa faixa. Com a dose ótima de $\mathrm{N}$ para a produção, os níveis críticos estimados dos teores de $\mathrm{N}$ na folha foram $61 ; 56$ e $51 \mathrm{~kg}^{-1}$, aos 50, 64 e 78 dias após a semeadura, indicando a necessidade de padronizar a época de amostragem. Assim, a maior produção de cabeça de repolho foi de $1,13 \mathrm{~kg}$ obtido com a dose de $277,8 \mathrm{~kg} \mathrm{~N} \mathrm{ha}^{-1}$. Com a dose ótima de $\mathrm{N}$ para a produção, os valores máximos estimados para os teores foliares de $\mathrm{N}-\mathrm{NO}_{3}$ e de nitrogênio total variaram com a época de amostragem. O período inicial de maior acúmulo de massa seca variou com as doses de nitrogênio.

\section{AGRADECIMENTOS}

À FAPEMIG pelo auxílio financei- ro concedido para a realização deste trabalho e pelas bolsas BIPDT e pósdoutorado.

\section{REFERÊNCIAS}

AQUINO LA; PUIATTI M; PEREIRA PRG; PEREIRA FHF; CASTRO MRS; LADEIRA IR. 2005a. Características produtivas do repolho em função de espaçamento e doses de nitrogênio. Horticultura Brasileira 23: 266-270.

AQUINO LA; PUIATTI M; PEREIRA PRG; PEREIRA FHF; LADEIRA IR; CASTRO MRS. 2005b. Efeito de espaçamentos e doses de nitrogênio sobre as características qualitativas da produção do repolho. Horticultura Brasileira 23: 100-104.

BENINCASA MMP. 1988. Análise de crescimento de plantas: noções básicas. Jaboticabal: UNESP-FCAV, 41p.

CARDOSO AII; HIRAKI H. 2001. Avaliação de doses e épocas de aplicação de nitrato de cálcio em cobertura na cultura do rabanete. Horticultura Brasileira 19: 328-331.

CATALDO DA; HARRON M; SCHRADER LEL; YOUNGS VL. 1975. Rapid colorimetric determination of nitrate in plant tissue by nitration of salicylic acid. Communications in Soil Science and Plant Analysis 6: 71-80.

DIN M; QASIM M; ALAM M. 2007. Effect of different levels of N, P and $\mathrm{K}$ on the growth 
and yield of cabbage. Journal of Agriculture Research 45: 171-176.

EKBLADH G; WITTER E; ERICSSON T. 2007. Ontogenetic decline in the nitrogen concentration of field grown white cabbage - Relation to growth components. Scientia Horticulturae 112: 149-155.

FERREIRA WR; RANAL MA; FILGUEIRA FAR. 2002. Fertilizantes e espaçamento entre plantas na produtividade da couve-da-malásia. Horticultura Brasileira 20: 635-640.

FILGUEIRA FAR. 2007. Novo Manual de Olericultura: agrotecnologia moderna na produção e comercialização de hortaliças. 3 ed. Viçosa: UFV. 421p.

FUNARBE - SAEG. Sistema para Análises Estatisticas. v. 5.0. Viçosa, 1993.

HAQUE KMF; JAHANGIR AA; HAQUE ME,
ONDAL RK; JAHAN MAA; SARKER MAM. 2006. Yield and nutritional quality of cabbages as affected by nitrogen and phosphorus fertilization. Journal Science Indian Research 41: 41-46.

HUANG SW; JIN JY; YANG LP; BAI YL; LI CH. 2004. Spatial variability of nitrate in cabbage and nitrate-N in soil. Soil Science 169: 640-649.

HUETT DO; DETTMANN EB. 1989. Effect of nitrogen on growth, quality and nutrient uptake of cabbages grown in sand culture. Australian Journal of Experimental Agriculture 29: 875-881.

KANO Y; NAKAGAWA H; SEKINE M; GOTO H; SUGIURA A. 2007. Effect of nitrogen fertilizer on cell size and sugar accumulation in the leaves of cabbage (Brassica oleracea L.). HortScience 42: 1490-1492.
TORRES JLR; FABIAN AJ; POCAY VG. 2003. Níveis de adubação nitrogenada nas características morfológicas e produtivas do jiló. Horticultura Brasileira 21: 167-170.

TRANI PE; RAIJ B van. 1996. Hortaliças. In: RAIJ B van; CANTARELLA H; QUAGGIO JA; FURLANI AMC. Recomendações de adubação e calagem para o Estado de São Paulo. 2ed. Campinas: Instituto Agronômico/ Fundação IAC: 157-185.

VIDIGAL SM; PEREIRA PRG; PEDROSA MW. 2007. Repolho. In: PAULA JÚNIOR TJ; VENZON M (coords) 101 Culturas: manual de tecnologias agrícolas. Belo Horizonte: EPAMIG: 655-674.

WESTERVELD SM; MCKEOWN AW; SCOTTDUPREE CD. 2004. Assessment of chlorophyll and meters as field tissue nitrogen test for cabbage, onions and carrots. HortTechnology 14: $179-188$. 